\title{
Effects of an Interpersonal Style Intervention for Coaches on Young Soccer Players' Motivational Processes
}

\author{
by \\ Juan J. Pulido ${ }^{1}$, David Sánchez-Oliva ${ }^{1}$,Francisco M. Leo ${ }^{2}$, Sergio Matos ${ }^{1}$, \\ Tomás García-Calvo ${ }^{1}$
}

\begin{abstract}
The main goal of the study was to assess the effects of an intervention programme developed with soccer coaches, based on promoting strategies to optimise the satisfaction of the basic psychological needs of athletes. Eight soccer coaches, aged between 19 and 50 years $(M=32.5 ; S D=14.34)$, participated in the study. They were selected intentionally (without academic or federative training) and divided equally into a control and an experimental group by random peer selection. Also, 109 soccer players, aged between 11 and 15 years $(M=13.78 ; S D=1.38)$, divided into a control group (CG; $n=56)$ and an experimental group (EG; $n=53)$, participated in the experiment. The training programme (12 hours) was aimed to develop methodological and motivational strategies to promote autonomy, competence and relatedness need satisfaction among the players. The results showed that the participants in the EG decreased competence and relatedness control, while significantly increased (post-intervention) competence and relatedness needs satisfaction. Moreover, values for the EG did not decrease for autonomy, competence frustration and amotivation, while they increased for the sport commitment. Also, intrinsic motivation decreased in both groups (greater decrease in the CG). In conclusion, we can affirm the effectiveness of the training programme to create an environment of "bright side" motivation, and reduce thwarting styles, needs frustration and low self-determination levels.
\end{abstract}

Key words: basic psychological needs, coaches, interpersonal style, intervention, self-determination.

\section{Introduction}

Despite the dissemination of knowledge concerning the importance of physical activity (PA) for a healthy life and optimal quality of life, data relating to physical inactivity globally remain alarming, affecting more the early stages of life, such as childhood and adolescence (Kohl et al., 2012). Thus, there is a significant trend for study analysing what variables are essential for continuation in PA. Bauman et al. (2012) developed an interesting contribution in an attempt to uncover the main predictors of PA practice (or lack of), highlighting motivation as one of the best predictors.

Regarding to this, one of the most widely used theories to assess the type of motivational regulation is the Self-Determination Theory (SDT) (Deci and Ryan, 1985; 2000). Ryan and Deci (2000) point out that for a person to develop selfdetermined motivation, they must have covered three basic psychological needs, or at least not to have them frustrated (Ryan and Deci, 2000). These are (i) autonomy need (freedom of a person to carry out the activity, understand their own actions and guide their behaviour deliberately), (ii) competence need (positive feelings about ability levels, defined in terms of efficacy) and (iii) relatedness need (personal satisfaction in integrating with the immediate environment

\footnotetext{
1 - Faculty of Sport Science, University of Extremadura.

2 - Faculty of Education, University of Extremadura.
} 
during an activity).

Furthermore, SDT (Deci and Ryan, 1985; 2000) considers motivation to be a continuum, with different levels ranging from highest to lowest self-determination: autonomous motivation, controlled motivation and amotivation. The highest level is (i) autonomous motivation (intrinsic and identified), defined because the activity itself is pleasant and provides benefits perceived by its practitioners; next, (ii) controlled motivation (introjected and external) characterised as the activity performed to avoid guilt, or to get a reward or reinforce a change; finally, at the lowest level of self-determination, there is (iii) amotivation, characterised by the absence of extrinsic and intrinsic regulations and finding no reason to continue doing the activity.

Within SDT, the mini-theory of Cognitive Evaluation (Deci and Ryan, 1985; Ryan and Deci, 2000) focuses on the explanation of the social factors that can promote psychological needs. Focusing on the sporting context, Mageau and Vallerand (2003) indicated the coach as one of the most relevant agents to promote appropriate needs satisfaction and, consequently, selfdetermined motivation (Figure 1). Thus, how coaches influence their athletes has been extensively studied (Amorose and AndersonButcher, 2007; Conroy and Coatsworth, 2006; Pulido et al., 2014; Torregrosa et al., 2008), demonstrating the impact of these socialising agents on the motivational processes in athletes. For this reason, this study sought to produce an effective programme to optimise the training environment of young players by training their coaches, based on the promotion of methodological and motivational strategies.

Coach-athlete training environment: incidence of psychological needs

To ensure positive states in young soccer players, coaches can either create an inclusive environment that takes into account psychological needs (Ryan and Deci, 2000), or they can reduce the innate development of part in athletes by using thwarting behaviour (Reeve, 2009). For example, to develop (i) autonomy support strategies, situations in which the opinions and decisions of the players are taken into account would be proposed, with players taking a leading role in designing them and with responsibility for their operation, evolving from more directive leadership styles towards a more democratic style (Mageau and Vallerand, 2003; Reeve, 2009). To develop (ii) competence support strategies, coaches should consider individualised learning rhythms (Jang et al., 2010), structuring tasks with clear guidelines and expectations (Sierens et al., 2009), setting challenges in tasks to the level and experience of the players, optimal time for efficacy and use of feedback, giving priority to the process (Koka and Hein, 2005). To develop (iii) relatedness support strategies, coaches should propose guidelines to facilitate the integration of all players, grouping strategies, dynamics of knowledge, development of social skills, etc. by investing time, energy and necessary resources (Grolnick and Ryan, 1989). It is also necessary to propose a task design involving a style of communication relationship support, which is characterised by the interaction and cooperation of the athletes in a warm atmosphere, with the coach showing a personal interest in them (Cox and Williams, 2008).

\section{Previous studies based on intervention with coaches}

Analysing previous studies that have developed intervention programmes to promote psychological needs satisfaction in adolescents, many of them in a physical education context (Aelterman et al., 2014; Cheon et al., 2012; Cheon and Reeve, 2013; Tessier et al., 2010), have shown positive effects of a teacher training programme based on implementing strategies to support psychological needs, inducing an increase in variables such as needs satisfaction, motivation, enjoyment, engagement and the intention to be physically active. Specifically, Tessier et al. (2010) revealed that from pre- to post intervention, teachers managed to improve their teaching style in terms of all three dimensions, and the students were receptive to these changes, as shown by increasing their reported need satisfaction, selfdetermined motivation and engagement in the class. Cheon et al. (2012), in a longitudinal study (three measures: at the beginning, middle, and end of the semester) and with a sample of 1158 students, showed that the students of the experimental group improved psychological need satisfaction, autonomous motivation, classroom engagement, skill development, future intentions, and academic achievement. In addition, Aelterman et al. (2014) showed changes in 
teachers' beliefs regarding both autonomy support and structure. As for teachers' actual teaching behaviour, the intervention was successful in increasing autonomy support according to students and external observers, while resulting in positive changes in teacherreported structure.

In a sporting context, and within the quasi-experimental studies based on the SDT (Deci and Ryan, 1985) and Achievement Goal Theory (AGT: Ames, 1992; Nicholls, 1989), the Promoting Adolescent Physical Activity project (PAPA: Duda et al., 2013) was designed and developed from an individualised behavioural goal-setting programme for coaches (Sousa et al., 2006, 2008). PAPA focused on soccer and had as its main axis training coaches to become aware of the nature of, and ways to improve, motivation in players through content and learning activities, optimising the motivational climate created by coaches, and by promoting well-being, perceived health and PA levels (Duda et al., 2013). On the other hand, some researchers such as Langdon et al. (2015), evaluated the effectiveness of a training program emphasizing the use of autonomy supportive coaching behaviours among youth soccer coaches in game-play situations as well as evaluating their effects on motivational processes among athletes. Findings indicated that youth sport coaches had the capacity to apply a moderate use of autonomy and relatedness supportive behaviours in game-play, while simultaneously providing high structure and low levels of relatedness thwarting behaviours.

However, as pointed out by Langan et al. (2013) in a systematic review: "Due to the diversity in athlete outcomes and intervention designs, it is difficult to draw firm conclusions around the effectiveness of coach education interventions. The small number of identified interventions highlights the current paucity of empirical data on coach education intervention effectiveness. More research is needed to further our understanding of intervention effectiveness to allow for growth and improvement in coach education. Furthermore, theory-based, rather than "theory inspired" coach education interventions are required".

Given the above, the objective of this study was to present an intervention programme based on the implementation of methodological and motivational strategies that would produce learning environments in which perceptions of coaches' interpersonal styles (supporting and thwarting styles), need satisfaction and need frustration, type of motivation and sport commitment of young soccer players were improved.

Therefore, this study attempted to examine the possible effects caused by an intervention programme developed with a group of coaches, based on SDT and focused on the promotion of methodological and motivational strategies. The general hypothesis of the study was that experimental group players, when compared to control group players, would show a positive evolution in perception ratings for supporting style, needs satisfaction, selfdetermined motivation and sport commitment. On the other hand, EG soccer players would show lower values for thwarting style, needs frustration, controlled motivation and amotivation than CG soccer players.

\section{Methods}

\section{Participants}

Coaches. A total of 8 male soccer coaches were divided into a Control Group (CG) $(n=4)$, aged between 19 and 50 years $(M=32.5 ; S D=$ 14.34), and an Experimental Group (EG) $(n=4)$, aged between 21 and 49 years $(M=28.5 ; S D=$ 13.67), with training experience of between 1 and 6 years $(M=3.00 ; S D=2.44)$ and between 3 and 10 years $(M=6.25 ; S D=2.87)$, respectively. The sample was selected intentionally, establishing the requirement to have had no sporting or academic training (i.e., eight coaches had no academic degree or any federative title to train). This was carried out by a random peer distribution to establish a normal partition of the categories of training and years of experience (two coaches for players aged 11 and 13 years, and two coaches for players aged 14 and 15 years for each group).

Soccer players. 109 male soccer players participated in the study, with a CG group of 56 players aged between 11 and 15 years $(M=13.57$; $S D=1.48)$ and an EG group of 53 players of the same age $(M=13.92 ; S D=1.23)$.

\section{Measures}

The study included five different questionnaires overall to measure:

Interpersonal Style: to assess the interpersonal style perceived the Coaches' 
Interpersonal Style-Questionnaire (CIS-Q; Pulido et al., 2017) was used. This scale is composed of 22 items that analyse autonomy support (4 items, e.g.: "Lets us make decisions during the development of the exercises"), competence support (3 items, e.g.: "Helps us to learn and improve in soccer") and relatedness support (4 items, e.g.: "Encourages all athletes to feel integrated"), as well as autonomy thwarting (4 items, e.g.: "Prevents us from making decisions about the way we play"), competence thwarting (3 items, e.g.: "Does not give me opportunities to show my potential") and relatedness thwarting (4 items, e.g.: "Creates an atmosphere in the team I do not like"). As the scale is a review process, it used a Confirmatory Factor Analysis with the following fit index (CFA): $\chi^{2} / d f=2.50 ;$ CFI $=.91$; $\mathrm{TLI}=.90 ; \mathrm{GFI}=.90 ; \mathrm{SRMR}=.05 ;$ and RMSEA $=.06$.

Needs Satisfaction: to analyse the players' need satisfaction level the adapted to soccer (Pulido et al., 2016) Basic Psychological Needs in Exercise Scale (BPNES; Vlachopoulos and Michailidou, 2006) was used. This scale is composed of 12 items that assess autonomy satisfaction (4 items, e.g.: "How to perform the exercises is how I would want to"), competence satisfaction (4 items, e.g.: "I think I can meet the requirement of training") and relatedness satisfaction (4 items, e.g.: "I feel very comfortable with my soccer teammates").

Needs Frustration: the Spanish version (Balaguer et al., 2010) of the Psychological Needs Thwarting Scale (PNTS; Bartholomew et al., 2010) was used. This scale is composed of 12 items grouped in three sub-scales, which examine autonomy frustration (4 items, e.g.: "I feel pushed to behave in certain ways"), competence frustration (4 items, e.g.: "There are situations where I am made to feel inadequate"), and relatedness frustration (4 items, e.g.: "I feel other people dislike me").

Types of Motivation: to examine the type of motivation of the players the Sport Motivation Questionnaire (Pulido et al., 2015) was used. This questionnaire is composed of 20 items grouped into autonomous motivation, which include intrinsic (4 items, e.g.: "Because for me sport is enjoyable and interesting"), and identified regulation (4 items, e.g.: "Because I could learn skills that could be used in other things in my life"), controlled motivation, which includes introjected (4 items, e.g.: "Because it's when I do not feel bad about myself") and external regulations (4 items, e.g.: "Because it makes me look better in front of my coach and teammates"), and amotivation (4 items, e.g.: "But I really feel I'm wasting my time").

Sport Commitment: to value the players' sport commitment levels, the factor of the Spanish version (Sousa et al., 2007) of the Sport Commitment Questionnaire (SCQ; Scanlan et al., 1993) was used (5 items, e.g.: "I am determined to continue practicing the sport next season").

All instruments had a response rate ranging from 1 (strongly disagree) to 5 (strongly agree).

\section{Experimental design}

At the beginning of the midseason, all participants performed a pre-test, completing all questionnaires included in the study. Next, the EG coaches participated in the training programme. After the intervention, constant contact with the coaches was maintained, with the goal to improve the learning acquired during the programme. To achieve this, before completing the post-intervention questionnaires, and six weeks after receiving training (to allow time for assimilation), a researcher recorded six training sessions and two matches to ensure that coaches applied the strategies developed during the training programme (a guide for each coach: https://drive.google.com/file/d/OB3TQZm_VAvFV MnRVTmVpdXNHUmc/view?usp=sharing):

practice time, participation of players, explaining the objectives, approach challenges, etc. After these recordings, coaches watched videos with their performances during training sessions; both aspects to strengthen and modify were explained to them. Finally, post-intervention measurement was performed with the soccer players.

\section{Training programme}

The training programme was supported in several research studies in an academic context with physical education teachers (Cheon et al., 2012; Jang et al., 2010; Tessier et al., 2010) and a sporting context with coaches was developed (Duda et al., 2013; Sousa et al., 2006), with duration of 12 hours, divided into two parts: 1) Contextualization and theoretical framework focused on SDT; 2) Methodological and motivational strategies to encourage autonomy needs, competence needs and relatedness need. 
Different audiovisual media were used, such as videos, pictures and dynamic presentations.

In the first part, contextualization and the theoretical framework that supported the research were explained: SDT and its relationship with sport, the importance of psychological needs, the influence of social factors (coaches) on selfdetermined motivation and how research had shown the importance of training programmes based on SDT in different contexts (i.e., academic, work and sport).

In the second part, different methodological and motivational strategies were discussed to optimise psychological needs levels. Firstly, for theoretical and practical strategies for autonomy needs, coaches were informed of the possibilities for teaching and leadership styles that existed and could be developed, the ability to encourage active participation of players and the progressive transfer of responsibility based on the cognitive level and experience. To achieve this, coaches should adopt leadership styles depending on needs and the situation, avoid behaviour of pressure and control, promoting players' involvement, report on the objectives of the task and listen to the views and perspectives of the players.

Thirdly, as competence needs strategies, coaches could adapt their instructions and explanations based on progress, the importance of feedback (Ryan and Deci, 2000), and reinforcement through content-focused on individualised learning and achievable challenges. Also, coaches should propose balancing tasks with difficulty/skill, allow enough time to complete them, providing equal opportunities for all and prioritising the process over the result.

Finally, regarding relatedness needs strategies, coaches should adopt an attitude of empathy, developing specific activities and using methodological strategies characterised by closeness, respect and complementarity (Smith et al., 2007), and developing warm and friendly communication. They should also develop activities (e.g.: group dynamics, role playing, trust activities, problem solving and social skills) and use clustering strategies to help integration and equal participation of soccer players. After the training programme, a period of six weeks was provided for coaches to consolidate and apply their learning.

During the training programme, coaches developed activities to assimilate these strategies. For example, for autonomy needs, in the section on styles of leadership, the coaches had to deal with a situation to solve a structure with straws, in two teams. The winning team was the one that built the highest and most stable structure from straw. In both groups there was the position of a captain, who took on a different role in each of the teams. In one of them, the captain tried to reach a consensus with other members as to the best approach, supporting the ideas of others and taking into account their contributions in the final decision. In the other team, the coach adopted an autocratic role and imposed his ideas without taking into account the views of others. This role was forced and played by a person other than the coaches.

\section{Design and Procedures}

The investigation complied with the rules established in the Declaration of Helsinki (1964). Researchers held meetings with clubs to request collaboration and provide information to the coaches who worked for each club. After obtaining permission from the clubs and verifying that the coaches were eligible to participate in the study, researchers informed the managers, coaches and athletes of the voluntary nature of the study and the confidential treatment of results, following the guidelines set by the American Psychological Association (2009). Clubs were provided with a model of informed consent for parents to sign in order to allow players to participate.

Following this process, the procedure was divided into the following steps: 1) Pre-test data collection, 2) Training programme, 3) Post-test data collection, 4) Counterbalancing. During preand post-test data collection, players, $30 \mathrm{~min}$ before the training session, attended upgraded rooms so they could fill out questionnaires comfortably. During this process, one researcher was present to help with questions. This process lasted approximately 20-25 min.

\section{Statistical analysis}

First, with the aim of knowing the descriptive results, we carried out a descriptive analysis of the total sample, as well as for each of the groups (control and experimental) in each of the measures (pre and post). Next, to determine 
the structure of the instrument, a factor analysis was conducted and the reliability index was calculated (Cronbach's alpha).

Secondly, in order to analyse the effects of the intervention programme a mixed model with repeated ANCOVA measures was constructed for each dependent variable in the study, including group and time as factors. The data were treated as a two-level model. Level 1 encompassed repeated measures of each variable, and represented the change expected in each member of the population during the time period under study (Singer and Willett, 2003). Level 2 consisted of between-group variance and represented the differences in growth rates between groups in random slope variables. For each analysis, we estimated seven variables: four fixed effects (Intercept, Group, Time, and Group*Time) and three random effects (Repeated measures variability, Between-players intercept variability and Between-players slope variability). Repeated measures were treated with an Autoregressive Homogeneous (AR1) covariance structure, Restricted Maximum Likelihood (REML) was used as an estimation method and random effects were analysed with Diagonal covariance types and a Wald test (Heck et al., 2010). The study utilised the SPSS 21.0 and AMOS 19.0 statistical programmes.

\section{Results}

\section{Preliminary analysis}

Table 1 shows the descriptive statistics and internal reliability (Cronbach's alpha) in the pre- and post-test. High values were obtained in the supporting style, needs satisfaction, selfdetermined motivation and sport commitment, while lower values were obtained in the thwarting style, needs frustration and amotivation. Also, the reliability indices (Table 1) can be considered acceptable (.61 to .86 in pre-test and .60 to .88 in post-test), with scores above .60 , because it was a standard exploratory factor analysis in which values around .70 are suitable.

\section{Intervention effects}

Table 2 shows the results of the analysis of the effects of intervention. The first column shows the estimated CG in the pre-test and it should be noted that all data are shown with significant values. At the beginning of the data collection, significant differences were recorded for competence thwarting and controlled motivation. Specifically, the interception of the CG for competence thwarting at baseline was 1.64 and for the EG it was $2.00(p<.01 ; .36)$. For controlled motivation, the CG obtained a value of 2.70, while the EG had an average of 3.25. This initial difference was significant $(p<.01 ; .55)$. Group effect (second column) refers to the difference in the estimation of the EG relative to the CG in the pre-test. Time effect indicates the slope in the dependent variable for the CG. Group*Time effect refers to the difference in the slope of the EG relative to the CG Social Factors - Interpersonal Style

According to supportive behaviours, the two groups were not significantly different at the initial measure. In terms of growth rates, CG soccer players presented a positive growth in autonomy support, while competence and relatedness support grew negatively (for competence support, $p<.05)$. There were no significant Group*Time effects, only a marginal and positive effect for competence support ( $p=$ .07). Considering thwarting behaviours, in the competence thwarting significant differences were found $(.36, p<.05)$. In terms of growth rates, all soccer players had a negative growth for autonomy thwarting, while competence and relatedness thwarting grew positively. There were significant Group*Time effects for competence ($.41, p<.05)$ and relatedness thwarting $(-.30, p<$ $.05)$.

\section{Mediators - Psychological Needs}

Taking into account the needs satisfaction, at the beginning the two groups were not significantly different. In terms of growth rates, CG soccer players had a negative growth for autonomy, competence and relatedness needs satisfaction (for competence satisfaction, -.24, $p<$ $.05)$. There were significant Group ${ }^{*}$ Time effects for both competence $(.36, p<.05)$ and relatedness needs satisfaction $(.46, p<.05)$. For the needs frustration, the two groups were not significantly different. In terms of growth rates, CG soccer players had a positive growth for autonomy, competence and relatedness needs frustration. There were no significant Group*Time effects, although the growth rate in the EG was negative. Regulations

With respect to motivation, significant differences were obtained in controlled 
motivation $(.56, p<.05)$. In terms of growth rates, all soccer players had negative growth for autonomous motivation, while controlled motivation and amotivation grew positively. There were no significant Group*Time effects for any of the three variables.

Outcomes

Finally, for sport commitment, the two groups were not significantly different. In terms of growth rates, CG soccer players presented a negative growth. There were no significant Group*Time effects, although the growth rate in the EG was positive.

\section{Random effects}

With regard to random effects (Table 2), for supporting and thwarting style variables, variability and intra-subject intersection in the pre-test were not significant $(p>.05)$. However, the intra-subject slope changed significantly in all variables $(p<.01)$ except competence thwarting. For needs satisfaction and needs frustration variables, variability and intra-subject intersection in the pre-test were not significant $(p>.05)$. However, there were intra-subject slope changes in autonomy and competence satisfaction $(p<.01)$ and in the autonomy frustration $(p<.01)$.

Considering the random effects in the three types of motivation in the pre-test, variability and interception were not significant ( $p$ $>.05$ ) in any of the variables, while the intrasubject slope changed in the autonomous motivation $(p<.01)$ and in the controlled motivation $(p<.01)$. Ultimately, regarding the random effects of the sport commitment, no significant differences $(p>.05)$ were found in the variability, interception and intra-subject slope.

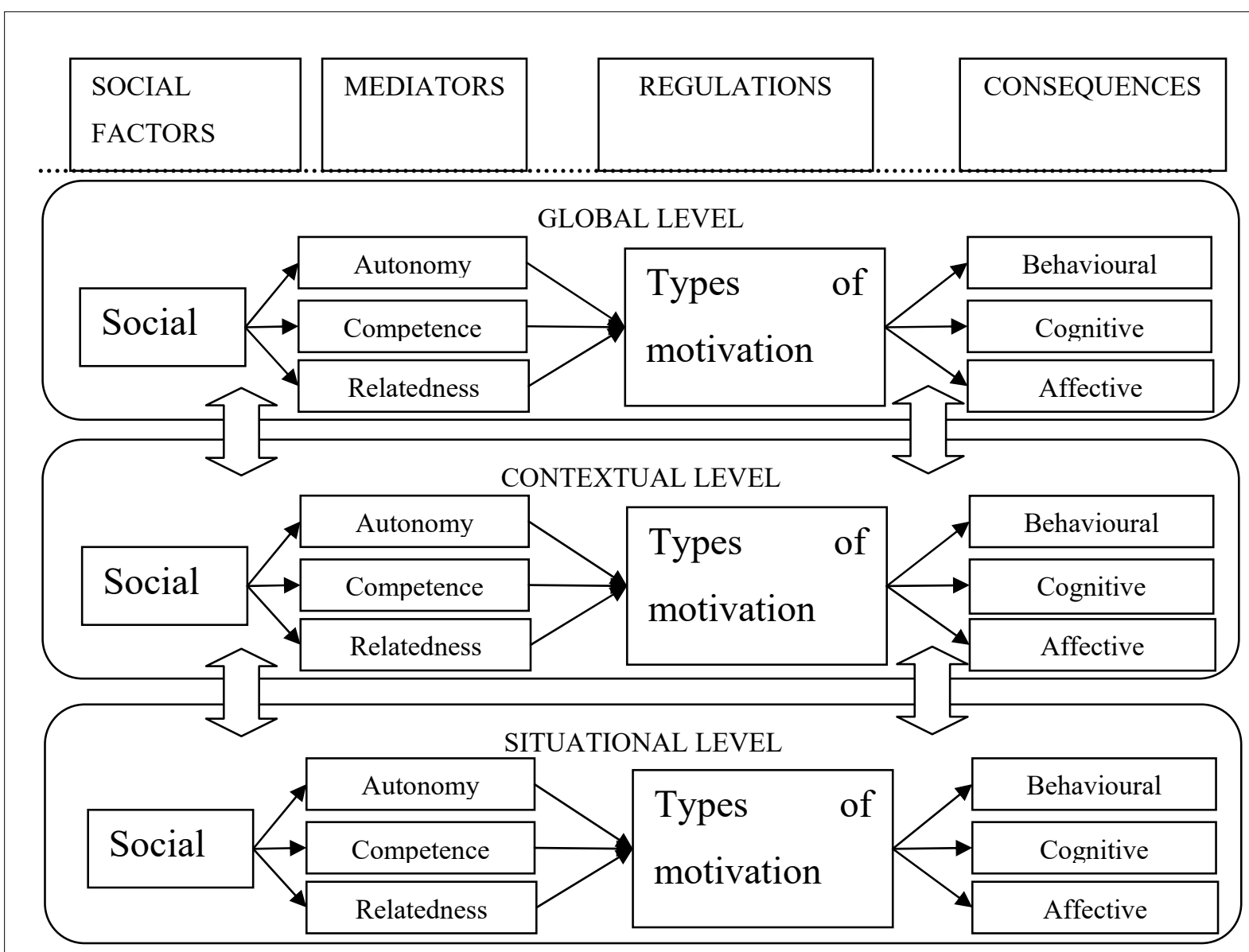

Figure 1

Vallerand's Hierarchical Model of Motivation (2001). 


\section{Table 1}

Descriptive statistics and reliability of the variables in the pre-test and post-test

\begin{tabular}{lllll}
\hline & \multicolumn{4}{l}{ Total Sample $(\mathrm{n}=109)$} \\
& Pre-test & & Post-test & \\
\cline { 2 - 5 } & $\mathrm{M}(\mathrm{SD})$ & $\alpha$ & $\mathrm{M}(\mathrm{SD})$ & $\alpha$ \\
\hline Autonomy Support & $3.11(.84)$ & .67 & $3.14(.98)$ & .81 \\
Competence Support & $4.38(.59)$ & .61 & $4.29(.64)$ & .70 \\
Relatedness Support & $4.36(.73)$ & .78 & $4.30(.76)$ & .84 \\
Autonomy Thwarting & $2.44(.81)$ & .62 & $2.32(.93)$ & .75 \\
Competence Thwarting & $1.81(.84)$ & .72 & $1.68(.74)$ & .68 \\
Relatedness Thwarting & $1.50(.68)$ & .74 & $1.55(.70)$ & .60 \\
Autonomy Satisfaction & $3.41(.73)$ & .62 & $3.38(.88)$ & .76 \\
Competence Satisfaction & $4.16(.57)$ & .61 & $4.09(.61)$ & .66 \\
Relatedness Satisfaction & $4.29(.73)$ & .73 & $4.32(.72)$ & .74 \\
Autonomy Frustration & $2.40(.83)$ & .64 & $2.44(.93)$ & .69 \\
Competence Frustration & $2.06(.90)$ & .69 & $2.00(.86)$ & .67 \\
Relatedness Frustration & $2.04(.84)$ & .64 & $2.16(.78)$ & .68 \\
Autonomous Motivation & $4.21(.65)$ & .77 & $4.11(.74)$ & .83 \\
Controlled Motivation & $3.04(1.05)$ & .85 & $2.97(1.11)$ & .88 \\
Amotivation & $1.39(.81)$ & .86 & $1.36(.76)$ & .80 \\
Sport Commitment & $4.52(.55)$ & .78 & $4.48(.67)$ & .76 \\
\hline
\end{tabular}

Table 2

Analysis of mixed models

\begin{tabular}{lccccccc}
\hline & \multicolumn{4}{c}{ Fixed effects } & \multicolumn{3}{c}{ Random effects } \\
\cline { 2 - 8 } & Intercept & Group & Time & $\begin{array}{c}\text { Group } \\
\text { Time }\end{array}$ & RHO & Intercept & Slope \\
\cline { 2 - 8 } Autonomy Support & $2.98^{* *}$ & .28 & .03 & .01 & $.12(12.57)$ & $.64(4.70)$ & $-.34(.07)^{* *}$ \\
Competence Support & $4.45^{* *}$ & -.14 & $-.19^{*}$ & $.21^{107}$ & $.27(.33)$ & $.29(.00)$ &.$- .14(.03)^{* *}$ \\
Relatedness Support & $4.39^{* *}$ & -.04 & -.17 & .21 & $.32(22.99)$ & $.41(5.75)$ & $-.18(.04)^{* *}$ \\
Autonomy Thwarting & $2.40^{* *}$ & .09 & -.14 & .03 & $-.04(.31)$ & $.51(.00)$ & $-.26(.07)^{* *}$ \\
Competence Thwarting & $1.64^{* *}$ & $.36^{*}$ & .07 & $-.41^{* *}$ & $.27(31.60)$ & $.34(8.87)$ & $-.09(.05)$ \\
Relatedness Thwarting & $1.41^{* *}$ & .20 & .20 & $-.30^{*}$ & $.02(60.24)$ & $.28(12.76)$ &.$- .12(.04)^{* *}$ \\
Autonomy Satisfaction & $3.43^{* *}$ & -.04 & -.14 & .24 & $-.01(.32)$ & $.48(.00)$ & $-.26(.06)^{* *}$ \\
Competence Satisfaction & $4.18^{* *}$ & -.04 & $-.24^{* *}$ & $.36^{* *}$ & $.03(38.55)$ & $.23(6.12)$ & $-.10(.03)^{* *}$ \\
Relatedness Satisfaction & $4.33^{* *}$ & -.09 & -.19 & $.46^{* *}$ & $-.17(.29)$ & $.25(.00)$ & $-.09(.05)$ \\
Autonomy Frustration & $2.29^{* *}$ & .23 & .10 & -.13 & $-.20(78.08)$ & $.45(27.08)$ & $-.24(.07)^{* *}$ \\
Competence Frustration & $1.98^{* *}$ & .17 & .08 & -.29 & $.04(40.31)$ & $.42(13.94)$ & $-.15(.06)^{*}$ \\
Relatedness Frustration & $1.95^{* *}$ & .18 & .12 & -.01 & $.03(35.00)$ & $.33(10.37)$ & $-.10(.06)$ \\
Autonomous Motivation & $4.13^{* *}$ & .17 & -.15 & .11 & $.23(38.54)$ & $.38(8.41)$ & $-.19(.04)^{* *}$ \\
Controlled Motivation & $2.70^{* *}$ & $.56^{* *}$ & .04 & -.07 & $.99(.00)$ & $.76(3.92)$ &.$- .23(.00)^{* *}$ \\
Amotivation & $1.30^{* *}$ & .18 & .12 & -.32 & $-.19(79.79)$ & $.24(22.04)$ & $-.07(.05)$ \\
Sport Commitment & $4.54^{* *}$ & -.02 & -.12 & .16 & $.60(5.49)$ & $.39(.77)$ &.$- .19(.02)^{* *}$ \\
\hline
\end{tabular}




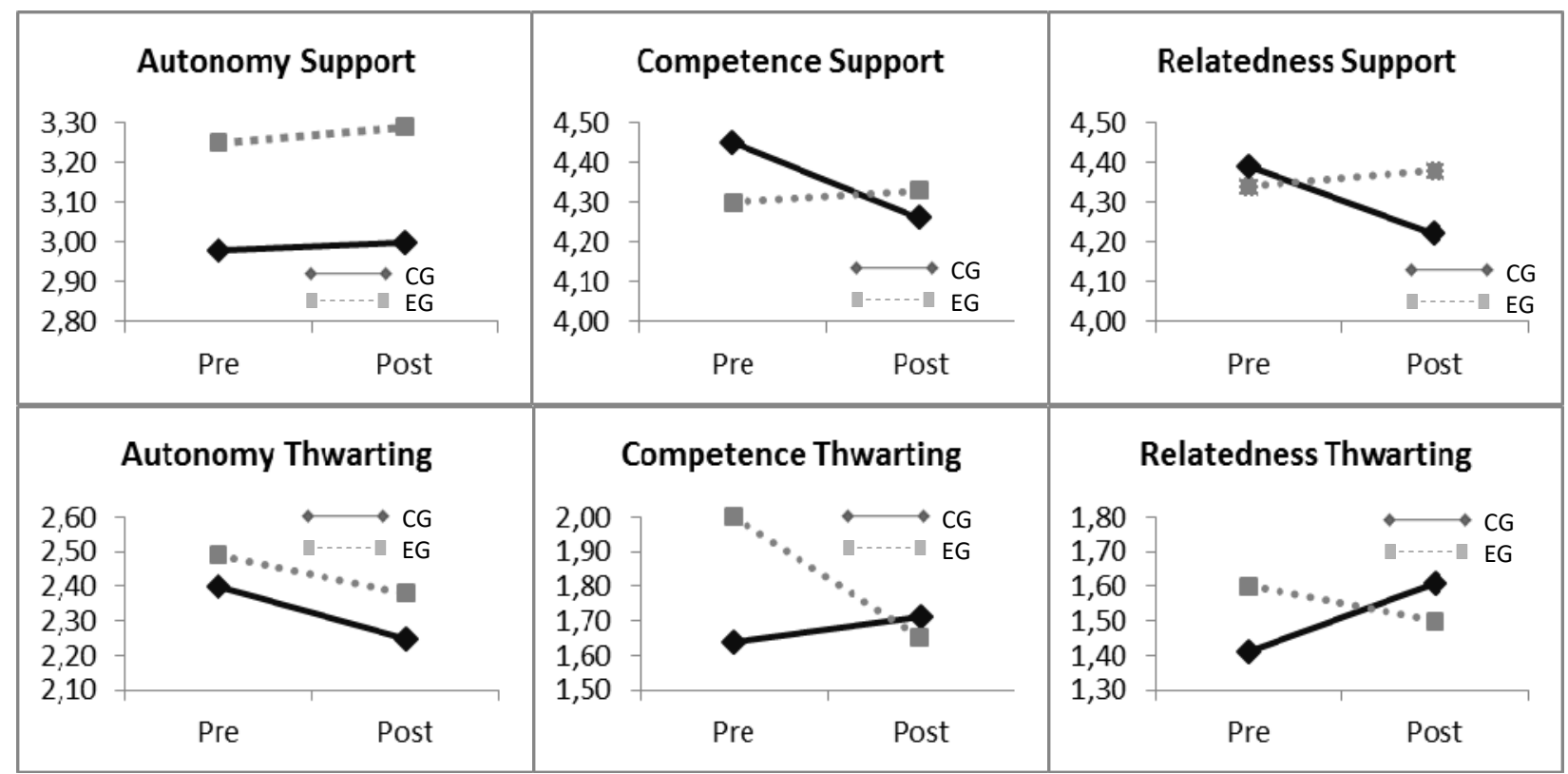

Figure 2

Values obtained in the supporting and thwarting style in the pre-test and post-test (control and experimental group).

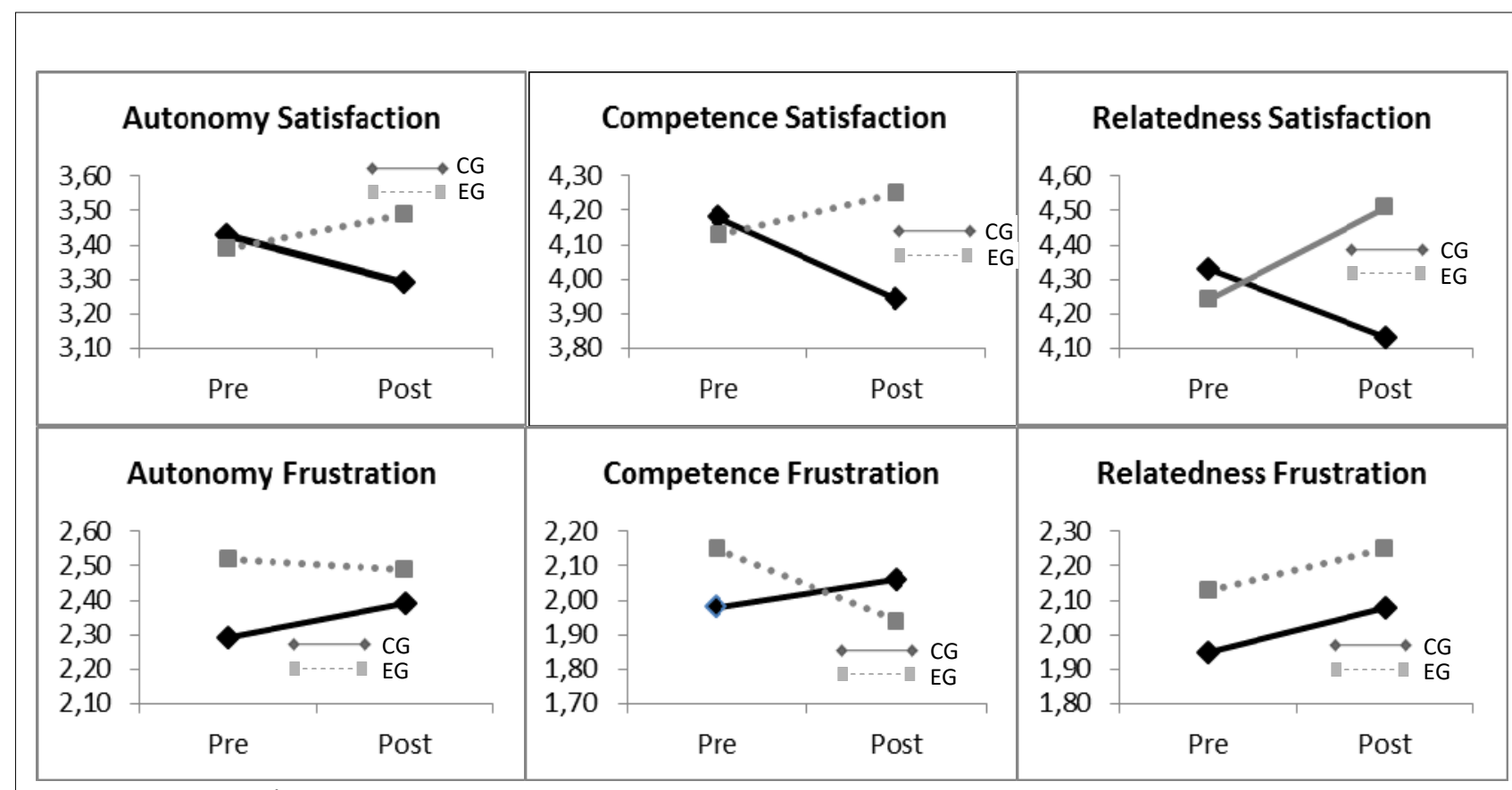

Figure 3.

Values obtained in need satisfaction and need frustration in the pre-test and post-test. 


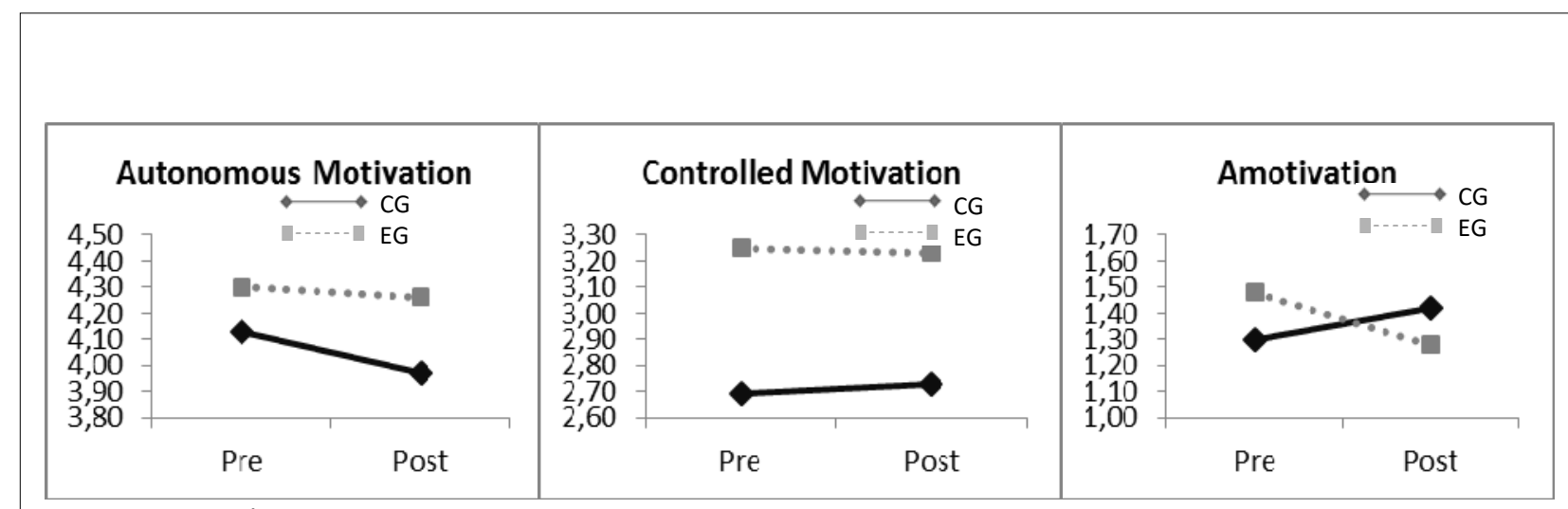

Figure 4

Values obtained in the types of motivation in the pre-test and post-test.

\section{Discussion}

The main aim of the study was to test the effectiveness of an intervention programme developed with soccer coaches and analyse its impact on the motivation and sport commitment of players. The results revealed differences between the CG and the EG in both measures. Specifically, the training programme received by coaches demonstrated its effectiveness in such variables as supporting style for the satisfaction of basic psychological needs, thwarting style and frustration of basic psychological needs, and amotivation, obtaining different and significant tendencies in both groups.
Assessing perceptions by players of the supporting or thwarting style of coaches in the pre-test, significant differences were obtained for competence thwarting. Nevertheless, taking into account the growth rates of both groups, significant scores were recorded in competence and relatedness thwarting, with differences in the growth rates of groups: decreasing levels in the EG and increasing levels in the CG. This shows that, after the intervention programme, coaches favoured a learning environment characterised by trying to train players with greater degrees of autonomy, competence and relatedness, that is, the programme changed the perception of players 
in a positive way. In addition, these results support those of Haerens et al. (2015), who found that a training programme developed for physical education teachers was effective in optimising the "bright side" (positive variables) of motivation and reducing levels of the "dark side" (negative variables). Similarly, Aelterman et al. (2014) developed an intervention that produced positive changes in teachers' beliefs regarding autonomy and structure. Consistent with this research, Langdon et al. (2015) developed a training program with youth sport coaches, who demonstrated to have the capacity to apply a moderate use of autonomy and relatedness supportive behaviours in game-play, while simultaneously providing high structure and low levels of relatedness thwarting behaviours. Therefore, the fact is that training programs yield results to improve interactions of agents of socialization, teacher-student or coach-athlete, optimizing the environment to promote the psychological needs.

In response to the effects on needs satisfaction and needs frustration, the results revealed significant differences in competence and relatedness satisfaction in the growth rates of both groups. Specifically, the CG values were compared to their pre-test, while the values for the EG increased, obtaining significant differences in the post-test between the two groups $(p<.01)$. For other variables of needs satisfaction and needs frustration, no significant differences were obtained, although autonomy satisfaction increased in the post-test in the EG and had lower values regarding the pre-test in the $C G$, so one can get a sense of the importance of training for maintaining or increasing autonomy satisfaction. In the same way, except relatedness frustration, all other variables grew in the CG and declined in the EG in the pre- and post-test, respectively. These results are similar to those of Balaguer et al. (2012) for needs satisfaction variables and Bartholomew et al. (2011) for needs frustration variables (thwarting in Bartholomew et al., 2011). However, these two studies (Balaguer et al., 2012; Bartholomew et al., 2011) are characterized by a cross-sectional design that did not include a training programme. Also, the results are consistent with Cheon et al. (2012), who developed a study with physical education teachers in which students showed an increase in needs satisfaction. In contrast, the results are contrary to those of Tessier et al. (2010), as these authors only found improvement in relatedness satisfaction, whereas in the current study this is the only variable where no difference in the growth rate between the groups was found.

Considering types of motivation, autonomous motivation decreased in the post-test in both groups. One explanation for this is that the more self-determined motivation over time (even during a season) can decrease, the more extrinsic motivation appears (Deci and Ryan, 1985). However, the decline in the EG was lower than that of the CG, thus the intervention program could make this decline occur more gradually. According to the controlled motivation, significant differences between both groups in the pre-test were shown $(p<.01)$, but after the training programme there were no significant differences in growth rates. Furthermore, despite having different rates and opposite growth for amotivation, these differences were not significant. These results partially correspond to those found by Tessier et al. (2010) and Cheon et al. (2012) in an academic context, and with Smith et al. (2007) in a sporting context, because they indicated a decline in extrinsic motivation and amotivation after the intervention, and an increase in autonomous motivation and task climate, respectively. However, if we look at both academic studies individually, in Tessier et al. (2010) no differences in self-determined motivation were shown, and in Cheon et al. (2012), no differences were recognised in extrinsic regulations and amotivation, so in general they resemble the results found in this research. One explanation for this may be that the training programme was focused on methodological and motivational strategies to promote the satisfaction of the basic psychological needs, thus motivation might be affected in the longer term and no variations would be obtained after only six weeks of application.

Finally, with regard to the values obtained for the sport commitment, no significant differences were shown, although the growth rate was different in both groups after the pre-test. Thus, as indicated in the hypothesis, CG soccer players showed lower values in the sport commitment, while EG soccer players showed increased sport commitment after the training 
programme. These results are similar to those found by other studies that analysed the impact of teachers and coaches on commitment, engagement or intention to be physically active (Cheon et al., 2012; Haerens et al., 2015; Tessier et al., 2010).

\section{Limitations, practical applications and conclusion}

First, some results were not significant. However, the trend of the results is consistent with the hypotheses for both groups, except for relatedness frustration and autonomous motivation. Possible practical applications are to develop intervention programmes in other sports and with female athletes. Also, it may be interesting to analyse the effects of such initiatives with semi-professional soccer teams. Finally, assessments by the coaches of the intervention programme could be included.

In conclusion, from the results of this research, we can affirm the effectiveness of the training programme based on SDT to create an environment of "bright side" motivation, and reduce thwarting styles, needs frustration and low self-determination levels. Another conclusion is that the training programme was not extensive, but it was possible to improve the skills and resources of coaches without sporting or academic training, which was reflected in their young soccer players' motivational backgrounds, types of motivation and sport commitment.

\section{Acknowledgements}

European Social Foundation and the Ministry of Enterprise, Innovation and Competitiveness (Government of Extremadura) - "PD12112". Also, thank American Journal Experts for carrying out the process of translation.

\section{References}

Aelterman N, Vansteenkiste M, Van den Berghe L, De Meyer J, Haerens L. Fostering a need-supportive teaching style: intervention effects on physical education teachers' beliefs and teaching behaviors. I Sport Exercise Psy, 2014; 36(6): 595-609. doi:10.1123/jsep.2013-0229

American Psychological Association. Publication Manual of the American Psychological Association, Sixth Edition; 2009

Ames C. Classrooms: goals, structure, and student motivation. J Educ Psychol, 1992; 84(3): 261-271. http://psycnet.apa.org/doi/10.1037/0022-0663.84.3.261

Amorose AJ, Anderson-Butcher D. Autonomy-supportive coaching and self-determined motivation in high school and college athletes: A test of self-determination theory. Psychol Sport Exercise, 2007; 8(5): 654670. doi:10.1016/j.psychsport.2006.11.003

Balaguer I, Castillo I, Mercé J, Ródenas LT, Rodríguez A, García-Merita M, Ntoumanis N. Psychological Need Thwarting Scale in the sport context: Analysis of psychometric properties. Paper presented at VII Iberoamerican Congress of Psychology, Oviedo, Asturias (Spain)

Balaguer I, González L, Fabra P, Castillo I, Mercé J, Duda JL. Coaches' interpersonal style, basic psychological needs and the well- and ill-being of young soccer players: a longitudinal analysis. $J$ Sport Sci, 2012; 30(15): 1619-1629. doi:10.1080/02640414.2012.731517

Bartholomew KJ, Ntoumanis N, Thøgersen-Ntoumani C. The thwarting interpersonal style in a coaching context: Development and initial validation of a psychometric scale. J Sport Exercise Psy, 2010; 32: 193-216. https://doi.org/10.1123/jsep.32.2.193

Bartholomew KJ, Ntoumanis N, Ryan RM, Bosch JA, Thogersen-Ntoumanis C. Self-determination theory and diminished functioning: the role of interpersonal control and psychological need frustration. Pers Soc Psychol B, 2011; 37(11): 1459-1473. doi:10.1177/0146167211413125

Bauman AE, Reis RS, Sallis JF, Wells JC, Loos RJ, Martin BW, Lancet Physical Activity Series Working Group. Correlates of physical activity: why are some people physically active and others not? Lancet, 2012; 380(9838): 258-271. doi:10.1016/S0140-6736(12)60735-1 
Cheon SH, Reeve J, Moon IS. Experimentally based, longitudinally designed, teacher-focused intervention to help physical education teachers be more autonomy supportive toward their students. J Sport Exercise Psy, 2012; 34: 365-396. https://doi.org/10.1123/jsep.34.3.365

Conroy DE, Coatsworth JD. Coach training as a strategy for promoting youth social development. Sport Psychol, 2006; 20: 128-144. https://doi.org/10.1123/tsp.20.2.128

Conroy DE, Coatsworth JD. Assessing autonomy-supportive coaching strategies in youth sport. Psychol Sport Exercise, 2007; 8: 671-684. doi:10.1016/j.psychsport.2006.12.001

Cox A, Williams L. The roles of perceived teacher support, motivational climate, and psychological need satisfaction in students' physical education motivation. J Sport Exercise Psy, 2008; 30: 222-239. https://doi.org/10.1123/jsep.30.2.222

Deci E., Ryan RM. Intrinsic motivation and self-determination in human behavior. New York: Plenum Press; 1985

Deci EL, Ryan RM. The "what" and "why" of goal pursuits: Human needs and the self-determination of behaviour. Psychol Inq, 2000; 11: 227-268. http://dx.doi.org/10.1207/S15327965PLI1104_01

Declaration of Helsinki. World Medical Association. Ferney-Voltaire: AMM; 1964

Duda JL, Quested E, Haug E, Samdal O, Wold, B, Balaguer I, Castillo I, Sarrazin P, Papaioannou A, Ronglan LT, Cruz J, Hall H. Promoting Adolescent health through an intervention aimed at improving the quality of their participation in Physical Activity. Intern J Sport Exercise Psychol, 2013; 11(4): 319-327. doi:10.1080/1612197X.2013.839413

Grolnick WS, Ryan RM. Parent styles associated with children's self-regulation and competence in school. J Educ Psychol, 1989; 81: 143-154. doi:10.1037/0022-0663.81.2.143

Haerens L, Aelterman N, Vansteenkiste M, Soenens B, Van Petegem S. Do perceived autonomy-supportive and thwarting teaching relate to physical education students' motivational experiences through unique pathways? Distinguishing between the bright and dark side of motivation. Psychol Sport Exercise, 2015; 16(3): 26-36. doi:10.1016/j.psychsport.2014.08.013

Heck RH, Thomas SL, Tabata LN. Multilevel and longitudinal modelling with IBM SPSS. Taylor \& Francis; 2010

Hox J. Multilevel analysis: Techniques and applications. Routledge; 2010

Jang H, Reeve J, Deci EL. Engaging students in learning activities: It is not autonomy support or structure but autonomy support and structure. J Educ Psychol, 2010; 102: 588-600. http://dx.doi.org/10.1037/a0019682

Kohl HW, Craig CL, Lambert EV, Inoue S, Alkandari JR, Leetongin G, Kahlmeier S, Lancet Physical Activity Series Working Group. The pandemic of physical inactivity: global action for public health. Lancet, 2012; 380(9838): 294-305. doi:10.1016/S0140-6736(12)60898-8

Koka A, Hein V. The effect of perceived teacher feedback on intrinsic motivation in physical education. Intern J Sport Psychol, 2005; 36: 91-106

Langan E, Blake C, Lonsdale C. Systematic review of the effectiveness of interpersonal coach education interventions on athlete outcomes. Psychol Sport Exercise, 2013; 14(1): 37-49. doi:10.1016/j.psychsport.2012.06.007

Langdon J, Schlote R, Harris B, Burdette G, Rothberger S. Effects of a training program to enhance autonomy supportive behaviors among youth soccer coaches. J Hum Sport Exercise, 2015; 10(1): 1-14. doi:10.14198/jhse.2015.101.0

Mageau GA, Vallerand RJ. The coach-athlete relationship: a motivational model. J Sport Sci, 2003; 21(11): 883-904

Moreno JA, González-Cutre D, Chillón M, Parra N. Adaptation of the Basic Psychological Needs in Exercise Scale to Physical Education. Rev Mex Psicol, 2008; 25(2): 295-303

Mouratidis A, Vansteenkiste M, Sideridis G, Lens W. Variation in vitality and interest-enjoyment as a function of class-to-class need-supportive teaching and pupils' autonomous motivation. $J$ Educ Psychol, 2011; 103: 353-366. doi:10.1037/a0022773

Nicholls JG. The competitive ethos and democratic education. Cambridge, MA: Harvard University Press; 1989 
Pulido JJ, Sánchez-Oliva D, Amado D, González-Ponce I, Sánchez-Miguel PA. Influence of motivational processes on enjoyment, boredom and intention to persist in young sportspersons. $S$ Afr J Res Sport, Phys Educ Rec, 2014; 36(3): 135-149

Pulido JJ, Sánchez-Oliva D, González-Ponce I, Amado D, Montero C, García-Calvo T. Adaptation and validation of a questionnaire to assess motivation in the sport context. Cuadernos Psicol Deporte, 2015; 15(3): 17-26

Pulido JJ, Sánchez-Oliva D, González-Ponce I, Amado D, Chamorro JL. Adaptation of the Basics Psychological Need Exercise Scale to the football. Rev Iberoamericana Psicol Ejercicio Deporte, 2016; 11(2): 177-184

Pulido JJ, Sánchez-Oliva D, Leo FM, Sánchez-Cano J, García-Calvo T. Development and validation of Coach's Interpersonal Style Questionnaire (CIS-Q). Meas Phys Educ Exercise Sci, 2017; 1-13. http://dx.doi.org/10.1080/1091367X.2017.1369982

Reeve J. Why teachers adopt a thwarting motivating style toward students and how they can become more autonomy supportive. Educ Psychol, 2009; 44: 159-175. doi:10.1080/00461520903028990

Ryan RM, Deci EL. Self-determination theory and the facilitation of intrinsic motivation, social development and wellbeing. Am Psychol, 2000; 55(1): 68-78

Scanlan TK, Simons JP, Carpenter PJ, Schmidt GW, Keeler B. The sport commitment model: Measurement development for the youth-sport domain. J Sport Exercise Psy, 1993; 15: 16-38

Sierens E, Vansteenkiste M, Goossens L, Soenens B, Dochy F. The synergistic relationship of perceived autonomy support and structure in the prediction of self-regulated learning. British J Educ Psychol, 2009; 79: 57-68. doi:10.1348/000709908X304398

Singer JD, Willett JB. Applied longitudinal data analysis: Modelling change and event occurrence. Oxford university press; 2003

Smith RE, Smoll FL, Cumming SP. Effects of a motivational climate intervention for coaches on young athletes' sport performance anxiety. J Clin Sport Psychol, 2007; 1: 23-46. http://opus.bath.ac.uk/6282/

Sousa C, Cruz J, Torregrosa M, Vilches D, Viladrich C. Behavioral assessment and individual counselling programme for coaches of young athletes. Rev Psicol Deporte, 2006; 15(2): 263-278

Sousa C, Torregrosa M, Viladrich C, Villamarín F, Cruz J. The commitment of young soccer players. Psicothema, 2007; 19: 256-262

Sousa C, Smith RE, Cruz J. An individualized behavioral goal-setting program for coaches. J Clin Sport Psychol, 2008; 2: 258-277

Tessier D, Sarrazin P, Ntoumanis N. The effect of an intervention to improve newly qualified teachers' interpersonal style, students motivation and psychological need satisfaction in sport-based physical education. Contemp Educ Psychol, 2010; 35: 242-253. doi:10.1016/j.cedpsych.2010.05.005

Torregrosa M, Sousa C, Viladrich C, Villamarín F, Cruz J. Motivational climate and coaches' communication style predict young soccer players' commitment. Psicothema, 2008; 20(2): 254-259

Vallerand RJ. A hierarchical model of intrinsic and extrinsic motivation in sport and exercise. In G.C. Roberts (Ed.): Advances in motivation in sport and exercise (pp. 263-319). Champaign, IL: Human Kinetics; 2001

Vlachopoulos SP, Michailidou S. Development and initial validation of a measure of autonomy, competence, and relatedness in exercise: The Basic Psychological Needs in Exercise Scale. Meas Phys Educ Exercise Sci, 2006; 10: 179-201

\section{Corresponding author:}

\section{Juan José Pulido González.}

Faculty of Sport Science, University of Extremadura. C/

Avenida de la Universidad s/n, 10071, Cáceres, Spain.

Email: jjpulido@unex.es 